\title{
Teaching and Ethics in Complexity Science: The Ethics of Absolute Unitary Being
}

\author{
JOYCE MGOMBELO \\ Brock University (Canada)
}

The paper argues for the significance of complexity science and its role in the ethics of teaching that is not based on moral codes. Through the work of Varela on human consciousness, and the work of Newburg and his colleagues on neurotheology, the paper explores the elements of human consciousness that are relevant for characterising an ethical act. Varela's concepts of emergent self and autopoiesis as well as Newburg's concept of Absolute Unitary Being provide the necessary conditions for characterizing an ethical act as essentially unconscious. Finally the paper discusses the implication of these contentions for ethics in teaching.

There are indeed among propositions, proposals, problems, questions, those that are decidable, and those that are in principle undecidable. ... Only those questions that are in principle undecidable, we can decide. (Heinz von Foerster, 1991, p. 64)

\section{Establishing a Ground for the Question of Ethics in Teaching}

I would like to begin my paper by presenting one of student narrative from my doctoral dissertation (Mgombelo, 2002):

\section{Queen-of-no-work, bright students}

I am experiencing a very broad range of students (from Math 7 students who cannot multiply to Math 31 [introductory calculus] students who are whizzing through limits). Luckily they are not all in the same class. I am finding it difficult 
to adjust assignments and homework to meet the needs of both ends of my classes. It sounded so easy in class to just diversify the work to suit the needs of individuals but I am finding the reality of managing 30 grade sevens makes it difficult to know them well enough to know what they need.

I have the Queen-of-no-work in my Math 7 class. I am truly astonished at her ability to avoid doing any work. She has a dozen new tactics and excuses for each class. Finally I figured out that she can barely do basic operations. Her work avoidance behaviours are really self-esteem survival skills-you can't fail if you don't get started. She really, truly cannot do the work. Now that I know what is going on I want to help but I do not know where to start. I feel like I am barely keeping up with the class as it is. Theory and practice seem miles apart sometimes. I have a few ideas but I don't know how successful I'll be.

I also have two very bright students who want to work ahead as that is what their last teacher allowed them to do. I have no objections to them doing that but it means I really need to get on top of the long-term plans and figure out what they should be doing. I can feel myself getting further behind as I write this. I'd better get back at it.

Reading this student teacher's narrative description of her experiences resonates with those of us who are involved with student teaching. We all know either from our own experiences as student teachers or from observing or supervising student teaching, how exciting and challenging the experience can be. Knowing this, it is possible to dismiss this narrative as a typical or expected experience for any student teacher. After all, with practice and experience, student teachers eventually overcome their initial difficulties. Yet, a closer reading of this narrative also reveals the day-to-day struggles that every teacher experiences in her classroom: how to act towards students, how to respond to different needs of our students, and so on. As Boaler (2002) notes, contrary to the implied meaning in some educational discussions, teaching is an action and not a knowledge base. As an action, teaching has consequences for students and society. It is for this reason that teaching is rooted fundamentally in ethics.

The question of ethics and teaching is not new in education. Three approaches of educational ethics can be identified. The first approach grounds ethics on some substantial notion of supreme Good. This approach has roots in the Judeo-Christian ethics that is anchored in the ethical law of the form "thou shall not" (von Foerster, 1994). As von Foerster notes, this is an ethics that assumes that a subject is separate from the world-it is an ethics of moral codes. In education, moral codes might be seen, for example, in rules that govern how teachers ought to behave towards students (e.g., students' rights that protect them from sexual or physical abuse from teachers).

The second approach challenges the substance and the universalism of the first by giving its universalism a proceduralist twist. This is an ethics that 
is based on utilitarianism. According to this approach the notion of "Good" can be decided based on whether or not it benefits the majority or minority in the community. It is an ethics founded on the calculation of the benefits. In teaching, this approach manifests itself in the practices that teachers employ in order to benefit the majority of their students. Incidentally, this must be the reason that advanced students are the most neglected group in schools. What does it mean when teachers say they teach the average in their classes? Does this mean that they teach the majority? We see this type of reasoning and decision making reflected in the student's narrative.

The third approach is what might be thought of as a post-modern option. Perhaps more important for educational ethics has been postmodernism's contribution of bringing into view the question of difference in education theory. By urging education theorists and researchers to be aware of the fictitious nature of truth, postmodernism reminds us not to impose our rules onto others (Zizek, 1997). The question of difference is crucial in teaching. Classrooms are places where one finds a plurality of identities such as gender, age, ability, culture, and so on. No doubt teachers encounter issues related to difference when making decisions on their actions, as is revealed in the above student narrative. Despite their challenge to the substance and universalism of the first option, the second and third options continue to function in the same way; they continue to privilege a certain positive content. Even though the post-modern approach challenges the notion of difference, it continues to impose some rules, albeit at a second-level: rules such as those of tolerance, of accepting irreducible difference and so on. ${ }^{1}$

The thesis that I attempt to bring in this paper is that there "exists" a different ethics in teaching that does not rely on rules or moral codes reflected in the above approaches. This type of ethics is at the centre of teaching as an action and as a human relationship. It is an open ethics, guided by an injunction of the form (to borrow from Kant) "do your duty." When, for example, I am confronted with a moral dilemma in my teaching, I do not stop and discern the options or rules that I have to choose, I just act and only after my action am I aware of what I have chosen. It is this ethics that I would like to explore in this paper, by drawing from domains of intellectual practice interested in those elements of human consciousness that are crucial for understanding human actions and relationships such as teaching. These comprise of domains, such as complexity science, neuroscience, enactivism and so on. I believe that the question of ethics in teaching cannot be dealt with satisfactorily without addressing ontological questions, such as the nature of human consciousness. This is especially important in this era, where more and more we are witnessing a dissatisfaction of the ethics grounded on objectivism and its dualistic notions (e.g., mind / body, particular/ universal, nature/culture and so on). This realization prompts us to re-think ethics as 
being something that is not based on objectivist assumptions that we are separate from our world. This is an ethics that is based on the fact that we are part of the world and are therefore responsible for our actions. As von Foerster states succinctly:

... if I consider myself as apart from the world then because of my independence I can tell others how to think and to act: 'Thou shalt ...,' 'Thou shalt not ....' However, if I consider myself as part of the world and as a participant in human relations and interactions then, because of my interdependence, I can only tell to myself how to think and to act: "I shall ...", "I shall not ...." (von Foerster, 1994)

For von Foerster, it is these two assumptions about our relationship with our world that distinguishes moral codes and ethics: the former is the origin of moral codes and the later is the origin of ethics. If we seriously consider what von Foerster seems to be alluding to here, then I will argue that, the question of the nature of human consciousness (of which we are as conscious or unconscious human beings) and how we come to make decisions and act given our condition as both interdependent and autonomous human beings, becomes more important in any exploration of ethics.

Like the question of ethics, the question of human consciousness is not new in educational theory and research. For some time now, educational theory and research have benefited from philosophies such as phenomenology, critical theory, poststructralism and postmodernism, which place human consciousness or subjective experience at the centre of any exploration. More recently there has been a growing interest in the study of consciousness in domains, such as hard sciences, cognitive science, neuroscience, quantum physics, chaos theory, complexity science and so on. Contrary to the perceived view of scientific exploration, which disregards subjective experience as noise and so forth, we are now witnessing the recognition of the study of human consciousness as a legitimate study in the laboratories of hard sciences.

I am interested in the work that studies human consciousness by drawing metaphors from the theory of complexity science. For this paper I will be relying heavily on the work of the late Francisco Varela (in collaboration with others for example, Maturana). My interest with Varela's work is twofold. First, I think the process of autopoiesis and the notion of emergence that Varela discusses allows one to understand those elements of human consciousness fundamental for human relations and actions central to the question of ethics. Secondly, Varela himself has taken this study further by considering the question of ethics in his work. In addition to this, I am also interested in the work of those researchers working in the field of neurotheology, a new discipline that considers theology from a neuroscience perspective. I am particularly interested in the celebrated work of Newburg, 
D'aquill and Rause in their book, Why God Won't Go Away: Brain Science and the Biology of Belief (2001). Newburg and his colleagues' notion of Absolute Unitary Being (AUB) as a state of pure awareness, experienced by both mystics during their prayers and Buddhist monks during meditation, provides us with insights on the nature of human consciousness and its relation to religious or spiritual experiences, which is also important in ethics. My hope is that by bringing these two works together, this will provide insights on the way we might think about ethics in teaching. More importantly, the merging of these works is also motivated by Varela's call for cognitive scientists to examine conscious experience that is cultivated by Buddhist contemplative practices, which were fundamental in Varela's work in ethics.

\section{Complexity Science and Human Consciousness}

The starting point of understanding human consciousness is to begin with the question of life as conceptualized by Valera and Maturana's notion of autopoiesis. In their seminal work on biology and cognition, Maturana and Varela (1971) introduced the idea of autopoiesis to show the organization of a minimal living system. According to Maturana and Varela, autopoiesis (from the Greek: self-producing) captures the mechanism or process that generates the identity of a living system and thus distinguishes living things from non-living things.

Autopoiesis attempts to define the uniqueness of the emergence that produces life in its fundamental cellular form. It's specific to the cellular level. There's a circular or network process that engenders a paradox: a selforganizing network of biochemical reactions produces molecules, which do something specific and unique: they create a boundary, a membrane, which constrains the network that has produced the constituents of the membrane. This is a logical bootstrap, a loop: a network produces entities that create a boundary, which constrains the network that produced the boundary. This bootstrap is precisely what's unique about cells. A selfdistinguishing entity exists when the bootstrap is completed. This entity has produced its own boundary. It doesn't require an external agent to notice it, or to say, "I'm here." It is, by itself, a self-distinction. It bootstraps itself out of a soup of chemistry and physics. (Varela, 1996, p. 212)

While the above explanation of an autopoietic system applies for a minimal or simple living system such as a cell, the same mechanisms can be applied to multicellular organisms (including human beings) with nervous systems. Thus:

I see the mind as an emergent property, and the very important and interesting consequence of this emergent property is our own sense of self. My sense of self exists because it gives me an interface with the world. I'm "me" for interactions, but my "I" doesn't substantially exist, in the sense 
that it can't be localized anywhere. This view, of course, resonates with the notions of the other biological selves I mentioned, but there are subtle and important differences. An emergent property, which is produced by an underlying network, is a coherent condition that allows the system in which it exists to interface at that level-that is, with other selves or identities of the same kind. You can never say, "This property is here; it's in this component." In the case of autopoiesis, you can't say that life-the condition of being self-produced-is in this molecule, or in the DNA, or in the cellular membrane, or in the protein. Life is in the configuration and in the dynamical pattern, which is what embodies it as an emergent property. (Varela, 1996, p. 215)

That is to say, "a self is precisely an entity without any substantial density without any hard kernel that will guarantee its consistency" (Zizek, 2004, p. 117). Its consistency is purely virtual. In other words, this emergent self is a virtual self, as there's no substance or hard core. Several conclusions might be drawn from this notion of autopoiesis. Based on what was stated above, it follows, that living things are characterized by an organization in which their only product is themselves (self-producing), with no separation between producer and product. Another significant observation might be in the way the local component levels relate to the global whole (emerging property-life) in an autopoietic system. According to Varela (1992a), autopoiesis helps us to see the relationship as a dialectic between the local component levels and global properties. They are linked together reciprocally through the requirements of constitution of an entity that self-separates from its background. This relationship, between the global effect and local components is very important in understanding the distinction between ethics based on moral codes and ethics that is of interest in this paper. The question to be answered is whether or not it is possible for an autopoietic system to have the will to act freely or with autonomy.

Let me reflect on this question by posing three scenarios with respect to the relationship of global property, such as self with the components at local level. In the first scenario, we will assume that there is only an upward cause that is responsible for the emergence of the self. The connectionist program in cognitive science, a program of which Varela was very critical, supports this scenario. If this is the case, then there will be no room for the self to practice free will or autonomy. For as 'self,' that just emerges from the interactions of local components, I will always be a 'victim' of these local interactions or processes. Consequently, when confronted by an ethical dilemma, I will act, but I cannot be held responsible for my actions because there is no other way I would act any differently. In teaching, this scenario is exemplified in those moments or situations that teachers face when confronted with ethical dilemmas and say "I am just a teacher and my job is to teach." 
The second scenario might be thought of as the Kantian moral program. It is noted that in his pursuit of a moral theory, Kant was aware of the necessity of the self that emerges from interactions of its local components-empirical or phenomenal, as well as the necessity of a free act or autonomy of self in moral theory (Zizek, 2004; Johnson, 1993). Kant's project was to ground ethics in a universal, moral law. For Kant the self that was to execute these universal laws was certainly not that of the empirical or phenomenal world with its pathological influences. To this end Kant has to postulate for a self-transcendental self or noumenal self (self in itself not affected by pathologies of the phenomenal world). Of course, as we might expect, by positioning this self apart from its world, Kant's moral theory failed in proving its purpose, forcing it to plunge into the moral codes of the form "Thou shalt not."

In the third scenario, Varela's program might be thought to rethink Kant without his notion of transcendentalism. That is to say, Varela rethinks the autonomy and free act of an emergent self together with its interdependence with its local processes. How is this possible? The solution lies in the notion of an autopoietic system as a complex dynamic system. As a complex system an autopoietic system is governed by indeterminacy or incompleteness of its local processes (Juarrero, 1999). It is this indeterminacy in the local processes that sustains the autonomy of the emergent self. The free act of the self can be thought of retroactively in the self reflexivity of the self. In other words, as an emergent self I am never entirely a victim of my local processes, as I always dispose a minimum freedom to determine which local processes will determine me (Zizek, 2004). This is the basis of the ethics that I am proposing in this paper.

The next significant contribution of Varela's work on the question of ethics might be sought from the nature of the relationship between an autopoietic system and its environment. Here we encounter the paradoxical nature of an autopoietic system: the system must distinguish itself from its environment, and must maintain its coupling with this environment simultaneously. This linkage cannot be detached since it is against this very environment from which the organism arises or comes forth. A very significant observation is that in this coupling between the living system and its environment, the balance is slightly weighted towards the living system; that is, it is the living system, which has the active role in the coupling. "In defining what it is as unity, in the very same movement it defines what remains exterior to it, that is to say its surrounding environment" (Varela, 199, p. 7). Varela explains that

... this exteriorization can only be understood, so to speak from the "inside": the autopoietic unity creates a perspective from which the exterior is one, which cannot be confused with the physical surroundings as they appear to 
us as observers, the land of physical and chemical laws simpliciter, devoid of such perspectivism. (Varela, 1992, p. 7)

On one hand, we have the environment of the living system as it appears to an observer, without reference to the autonomous unity. On the other hand, we have the environment of the system that is defined in the same movement that gave rise to its identity and that only exists in that mutual definition. Following Varela, we might call the environment of the system as simply environment and the environment for the system as its world. The difference between the environment and the world is the surplus signification. It is not that this surplus of signification is indifferent to the "laws" that operate in the environment, but the system's world is built on these laws, which are what ensures that it can maintain its coupling at all times. The difference between the environment and the system's world is important for understanding human relations, such as that between teacher and student. What this means is that there is irreducible otherness in our intersubjective relations. There is always something more (surplus signification) to the other subject that makes it impossible to know a person to their very being. It is this unknown quality of the other that illustrates the importance of maintaining ethical standards in forging any human relationship.

In the same token, as an emergent self or autopoietic system I cannot know myself in my being, there is always something more in me that eludes my grasp. As an autopoietic system, what I do is to constantly confront the encounters within my environment and treat them from a perspective that is not intrinsic to the encounters themselves. All this happens not from a sort of agent from the outside, but from the constitution of the system itself: with the dialectics between the local processes and the autopoietic unity, giving rise to its environment. "The constant bringing forth of signification is what we may describe as a permanent lack in the living: it is constantly bringing forth a signification that is missing, not pre-given or pre-existence" (Varela, 1992a, p. 8). ${ }^{2}$ Once again, even in this relationship between an autopoietic system and its environment we can see how its autonomy is maintained. We can also see that human action (cognitive or ethical) is essentially a free act.

The contentions raised in this section cannot be complete without addressing the question of self-consciousness or self-awareness. As von Foerster (1994) notes,

... the profound insight that it needs a brain to write a theory of the brain. From this follows that a theory of the brain that has any aspirations for completeness, has to account for the writing of this theory. And even more fascinating, the writer of this theory has to account for her- or himself. (p. 9)

That is to say, in order for these explorations of ethics to be meaningful we have to account for our experience of our form that "I have a body", as 
opposed to "I am a body". Put differently we have to take into account a problem that Varela was already aware of, our ego. In The Embodied Mind: Cognitive Science and Human Experience, Varela Thompson and Rosch (1991) urged cognitive scientists to reflect on human experience by learning from other traditions, such as Buddhism, which challenges the notion of the ego by juxtaposing it with the notion of no self. They contended:

We believe that the Buddhist doctrines of no-self and of non-dualism that grew out of this method (mindfulness meditation) have a significant contribution to make in a dialogue with cognitive science: (1) The no-self doctrine contributes to understanding the fragmentation of self portrayed in cognitivism and connectionism. (2) Buddhism non-dualism particularly as it is presented in the Madhyamika (which literally means "middle way") philosophy of Nagarjuna, may be juxtaposed with the entre-deux of Merleau-Ponty and with the more recent ideas of cognition as enaction. (pp. 21-22)

Later Varela, in Ethical Know-How (1999), elaborated more on this juxtaposition between cognitive science and Eastern traditions that explore human experience. It is noted that before his death Varela was interested in the exploration of the conscious experience (of no self) cultivated by Buddhist contemplative practices from the cognitive science itself. He named this inquiry neurophenomenology. It is after observing Varela's inquiry that I began to believe that it would be useful to incorporate Newburg and his colleagues work in neurotheology with Varela's work to develop my idea of ethics in teaching. My interest in this paper is in their notion of Absolute Unitary Being (AUB), a form of experience which is related to the experience of no-self or selfless. My intention is to explore the nature of this experience, as well as the nature of its relationship to our self-conscious experience. From this I hope to outline the place of AUB in ethics.

Although Newberg et al.'s research on the notion of AUB is interesting, in so far as it highlights the relationship between the brain and religious experience, there is a need to carefully evaluate their results before appropriating their implications for ethics. Neurotheology seeks to explain religious experience from the functions of the brain, based on the notion that there is a direct relationship between the brain and the experience. We need to carefully evaluate and distinguish this notion, as it is dealt with in science and its inherent appropriations, which might obfuscate its productive contribution to ethics. In the following section, I summarise Newburg and his colleagues' notion of AUB. I then discuss the ways that this notion might be misappropriated. Finally, I will discuss how by eliminating these misappropriations, AUB might help us to understand ethics in teaching. 


\section{Beyond Egoistic Individualism: The Absolute Unitary Being}

The basis of Newburg and his colleagues' work centres on the ability of the brain to process reality, with a particular emphasis on what they describe as the reality of religious experience. For Newburg and his colleagues the fundamental question about our reality is, 'how does the brain tell us what is real?' Newburg et al. use a device called single positron emission tomography (SPECT) to measure changes in blood flow that will identify brain areas and pathways that may be involved when the subject is in intense prayer and meditation.

The experimental subjects of this research include Buddhists monks and the Franciscan nuns. According to Newberg and his colleagues, both monks and nuns reported undergoing an intense experience that also involved the feeling of oneness with the universe, after prolonged prayer and meditation. They also explained how one comes to experience this transcendental state from the brain function perspective. The areas that are involved in religious experience include some of the oldest parts of the brain, such as the limbic system, as well as the areas connected to the autonomic nervous system and to the neocortical areas involved with goal and orientation behaviour. Newberg and his colleagues proposed that the sense of union experienced by nuns and monks during their peak moments in prayer and meditation, a sense that is also shared by mystics, occurs when some brain areas become activated while other brain areas become deafferented (i.e., cut off from their normal source of neural input). At the same time, the brain areas associated with emotions undergo various patterns of activity. While different parts of the brain (as mentioned above) are essential for Newberg et al.'s explanation of religious experience, it is "the orientation association area-the part of the brain that helps us distinguish the self from the rest of the world and orients that self in space" (Newburg et al., 2002, p. 87) that plays a big role in their explanation of religious experience.

The authors locate the orientation association area in the posterior superior parietal lobule of the brain. They suggest that when the right hemisphere's orientation association area gets completely cut off from its normal neural input, an experience of pure space occurs. When the left hemisphere's orientation area is cut off, a softening of a sense of self or selfless is experienced. These two effects, when combined with the patterns of activity occurring on those parts of the brain associated with emotions, results in the subjects' (in this case nuns or monks) attainment of a state of transcendence or absolute union, which Newberg et al. call the Absolute Unitary Being (AUB). "The transcendent state we call Absolute Unitary being, refers to a state of pure awareness, a clear and vivid consciousness of no-thing-yet it is also a sudden, vivid consciousness of everything as undifferentiated whole" (Newburg et al., 2002, p. 147). 
A key aspect of the notion of AUB is its link to the experience of no-self or self less, absolute union, emptiness, as described by mystics and Eastern traditions, such as Buddhism. It is this aspect, and its implication for ethics, that is of interest for this paper. However, let me first reflect on the way this notion of AUB might be misappropriated and obfuscate its productive aspects. It is not hard to see how the notion of Absolute Unitary Being can be misappropriated and made to function as the foundation for ethics based on moral codes. Just as I have argued earlier in the paper, two cases seem to present themselves here. First is the case of connectionist-reductionism misappropriation. Newberg and his colleagues noted that, "mystical experience is not as strange as it seems and the first step in understanding its nature is to realize that it happens to all of us, all the time" (Newburg et al., 2002, p. 113). Also, "like all experiences, moods and perceptions, these unitary states are made possible by neurological function. More specifically, they are the result of the softening of the sense of self and the absorption of the self into some larger sense of reality that we believe when the brain's orientation area is deafferented or deprived of neural input" (Newburg et al., 2002, p. 114). It is not difficult to see from these remarks the implicated logic of reductionist scientism, with regard to what counts as real. In his introductory remarks to his book, Newburg highlights what might be thought of as a breakthrough of their work in the field of science. He notes that for years people have been wondering about "the mysterious connection of human consciousness and the persistent and peculiarly human longing to connect with something larger than ourselves" (Newburg et al., 2002, p. 2). According to Newberg, people who meditate like Robert (one of the research subjects), claim that when they are in their peak experience of meditation, they experience a sense of deeper consciousness, that allows them to understand that the self is not a separate entity but is connected to every creation. When the subjects were asked to put their experience into words they "fall back into familiar clichés that have been employed for centuries to express the illusive nature of spiritual experience" (Newburg et al., 2002, p. 2), such as experiencing a sense of timelessness or infinity.

To the traditional scientific mind, of course, these terms are useless. Science concerns itself with that which can be weighed, counted, calculated, and measured - anything that can't be verified by objective observation simply can't be called scientific. Although individual scientist might be personally intrigued by Robert's experience, as professionals they'd likely dismiss his comments as too personal and speculative to signify anything concrete in the physical word. (p. 3)

That is to say, the significance and uniqueness of Newberg and his colleagues' work is to be able to show that experiences such as Robert's can be measured and verified by science, thus proving Robert's experience to be real. 
Thus, it only counts as real when it can be measured and verified by a scientific approach, however it is through these scientific methods that we can come closer to the objective reality, devoid of subjective impressions that might contaminate the results. As I have discussed before, this kind of thinking does not provide a full explanation of the event since the experience of human beings as autonomous autopoietic systems, is always already mediated by our actions. A report of this was illustrated in a documentary aired on Vision TV, in which one the scientists asserted to have been able to induce the mystic experience of the presence of God to ordinary people by manipulating their brains through some mechanism. To prove this, one popular atheist volunteered to be tested. When asked whether he was able to experience God's presence after the experiment the atheist answered, "not at all, it was just a weird experience." From this we are given to understand that the 'truth' of this occurrence depends on the subject's interpretation of their experience. What cannot be denied is that all had stated that some strange event had occurred. It follows from this observation that reality, what scientists call objective realty, is already presupposed by a scientist's distinction between objective reality and the subjective impressions of the researcher. Therefore, the difference between the AUB, as verified scientifically by Newberg and his colleagues, and the accounts of nuns and monks or mystics is not because the former is objective and the later subjective. The difference lies in the subjects' (scientist, nun, monks) presuppositions or judgments of what counts as reality. There is no neutral, external measure that allows us to judge that with Newberg's notion of ABU we come closer to the same reality or experience reported by nuns, Buddhists and mystics.

The second misappropriation, the Kantian transcendental notion of Absolute Unitary Being, is discernible in the interpretations that Newberg and his colleagues offer when they attempt to explore the question of reality in relation to the nature of this AUB from a neuroscientific perspective. For example, amazed by the reported experiences of this state by their subjects as "really real" or more real than our daily life reality, they noted:

Logic suggests that what is less real must be contained by what is more real, just as dream is contained within the mind of the dreamer. So, if Absolute Unitary Being truly is more real than subjective or objective reality-more real that is, than the external world and the subjective awareness of the self-then the self and the world must be contained within and perhaps created by the reality of AUB. (Newburg et al., 2002, p. 155)

What this line of reasoning seems to suggest, is that the reality of AUB is superior to our daily life reality. This second case involves a much more illusive appropriation of the notion of AUB by the so-called New Age movement. In this movement the notion of AUB might be taken to function as "the supplanting of the Cartesian mechanic-materialist paradigm by a new holistic approach bringing us back to the wisdom of oriental thought" (Zizek, 2002, 
p. 21). The danger that lurks from this new age appropriation is that this notion of AUB might begin to be taken as a spiritual supplement to the modern scientific reductionist-proceduralist mind of only that which can be weighed, calculated, and measured can be considered scientific (Newburg, d'Aquill \& Rause, 2001). The problem arises when, following this new age appropriation, one starts to legitimize one's position by invoking the authority of science itself. For example, when one is confronted by dilemmas and problems in day-to-day life, one need to just reason and rationalize that there is another reality which is more real than these day-to-day problems. Through this reasoning, these problems lose their power. Examples can be found in the new age language that supports this: go to your inner self, inner you and so on. What becomes lost in this kind of reasoning is the kind of subjective engagement that is crucial in thinking about ethics. The more fundamental question that arises from these misappropriations of the notion of AUB is whether we should simply renounce it as a mere reductionist scientific discovery or whether there another productive approach by which the notion can be used? My answer to this question is yes; there is a productive way.

\section{The Ethics of Absolute Unitary Being}

It is not hard to see how the two misappropriations of AUB discussed above rely on the notion of AUB as an objective truth, independent of the subjects; $\mathrm{AUB}$ as a presubjective neural event in the case of reductionism-connectionist approach and AUB as a transcendental-inner self in case of the New Age approach. If we do away with these misappropriations, what then is the nature of AUB? Stated differently, if AUB is not presubjective (neural), nor subjective (inner self), what then is the status of AUB? Perhaps the closest we might come to understanding the status of AUB is to think of it in terms of the Lacanian unconscious elaborated by Zizek (2000) below:

The identification with the mirror image is the identification with an object that effectively cannot ground the dimension of subjectivity; for that reason, this identification is alienating and performative: in the very act of recognizing myself as that image, I performatively posit that image as " $\mathrm{me}$ "- prior to it, I was nothing, I simply had no content. Who then is the "me" that recognizes itself as that image? The point is that this "nothing," previous to the imaginary recognition is not a pure absence but the subject itself, [Lacanian unconscious subject] that is, the void of self relating negativity, the substanceless $\mathrm{X}$ to which attitudes, desires and the like are attributed. I can not be acquainted with it precisely because its status is thoroughly non-phenomenological. (p. 27)

If we take the status of AUB to be without substance, non-phenomenological, in what ways then does AUB relate to our self-conscious (ego) experience? To answer this question, I invite the reader to observe the picture below, 
which was originally created by a Cartoonist W.E. Hill in 1915. If you are seeing this picture for the first time, I invite you to observe it before you continue reading this paper.

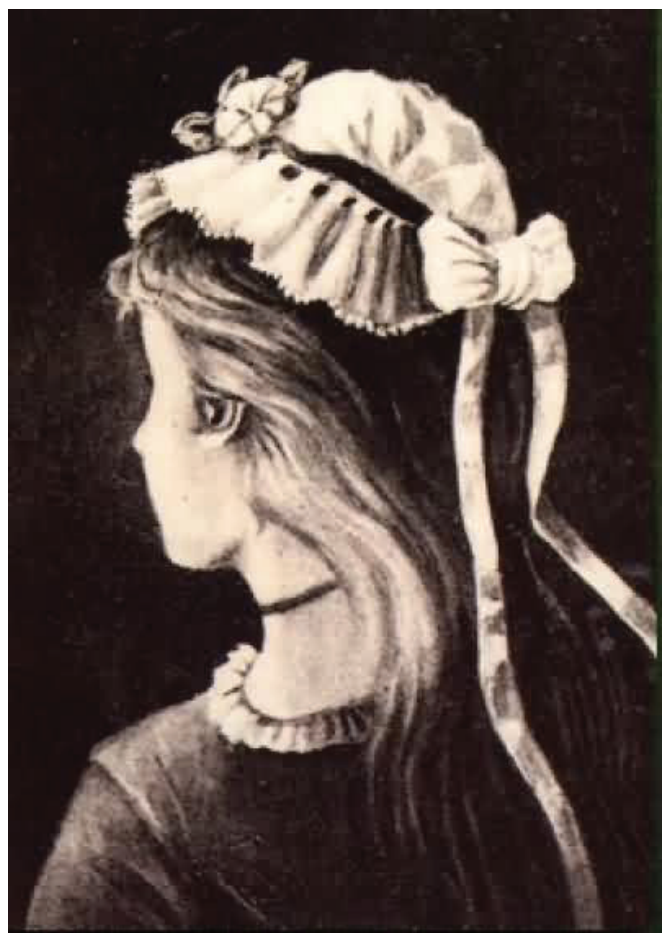

I suppose that the reader is able to see a young woman or an old woman. The first time I saw this picture I saw a young woman. I remember struggling to see the old woman, despite the clues that I was given. There are many interpretations one can make from this exercise. For the purpose of my arguments in this paper, the following observations are important. First, we should note that the young woman and old woman co-exist in one drawing. Secondly, even though they co-exist, it is impossible to see these pictures at the same time. No synthesis of the two pictures is possible.

I submit that it is in this kind of relation between the two pictures that we conceptualize the relation between AUB and our self-consciousness-ego experience. Conceptualized in this way, we can then observe that it is impossible to have these two experiences at the same time. This observation is supported by the people who meditate; the fact that after meditation they have a difficult time explaining what they experienced.

This impossibility is what the Enlightenment ideal of a self-awareness that enables us to act, of an empowering knowledge exemplified by the 
expressions like 'know-how' or 'savoir-faire', endeavour to elude: once I know too much, I am no longer in a position to accomplish the act-that is to say, a 'man who knows too much' is a man who can no longer act. (Zizek, 1996, p. 211)

From what has been covered thus far it can be understood that human action is essentially unconscious. Given this situation, I claim that the status of AUB is ethical, following Varela's (1999) articulation of "ethical action." In what ways then might AUB help us to understand ethics in teaching? To help us understand this I would like discuss an incident that happened in one of my pre-service teacher education classes.

It was the first day of class; the students had just finished their internship. As I have done this before, I started the class by asking each student to briefly talk about his or her internship experience. The students started talking, one by one. "My experience was wonderful. My cooperating teacher was so helpful" one student said. "I was so surprised to see that there are a number of students who lack basic math skills" another student continued. "I was amazed by the way students have come to depend on the calculator for simple calculation" another student explained. This went on for a while, with students, one by one talking about their experience and I, interjecting by making some comments or asking questions. It was now the turn for student who I will call X. "My experience was very good" he started talking. "I was actually having a good time. The students I was (sic) teaching did not know much. All I had to teach was very simple math" he continued. As he was talking he was actually smiling and gesturing (as it seemed to me) how he actually enjoyed this experience. I could not believe what I was hearing. For a while I stood there, silent. "Next" I ushered the next student to continue with her experience. After all the students had talked about their experiences I decided to give copies of course outline to the students. As I approached student X, I said "you can't be enjoying teaching simple math to these poor students; I think you need to ask yourself if you really want to be a teacher". Not only was I surprised by what I had just said, but also by the reaction of student $X$. He just looked at me with what appeared to be "an innocent child like look," not saying a single word!

I am sure this incident is not uncommon to teachers. I did not plan or know that I was going to say the words I spoke to student X. It is as if these words forced themselves out of my mouth. Of course the standard reaction to this kind of experience is to feel guilty and say "I am sorry I didn't mean that." But didn't I really mean that? It is here that I suggest that we locate the ethics of AUB. It is precisely because AUB is nonphenomenological that its effects are experienced in this way. There are no grounds for me to justify what I said. At best, all I can say I just did it. However, there is more to this story. Later on, when I reflected on this incident, I couldn't help but to ask myself what exactly did I expect my student to have done or behaved like with these students? I expected him to care for his students. What exactly did I mean by caring for students? One could say make math more fun to 
them or show that there was nothing wrong with them. In one of her writings, Mary Boole (1972) invokes a metaphor of figures of authority one could be or submit to: slave master, music conductor, and a shepherd. We know that a shepherd protects his sheep and feeds them well; but only in the end to send them to the slaughtering place! Do we not see here my own meaning of care? My encounter with my student was not an accident; it was my encounter with my "ego," manifested in what I have come to believe about teaching, as caring. For me this is the essence of the ethics of AUB in teaching. Varela (1999) offers a nice elaboration:

Th[e] sense of transformation does not mean going away from the world and getting out of mental functioning, since the very constituents on which the inaccurate sense of self and world are based are also the basis of wisdom. The means of transforming mental constituents into wisdom is intelligent awareness, that is, the moment-to-moment realization of the virtual self as it is-empty of any egoistic ground whatsoever, yet filled with wisdom. (Newburg et al., 2002, p. 73)

It is the moment-to-moment realization of AUB manifested in our contingent encounters with our students, that I submit is the essence of ethics in teaching.

\section{Conclusion}

In this paper I have attempted to argue for an ethics in teaching that is not based on moral codes, by bringing together the work of Varela on complexity science and the work of Newburg on neurotheology. Both Varela and Newburg conceptualize human consciousness in ways that imply that it is possible to ground this kind of ethics in teaching. Varela's notions of autopoiesis, and emergent self are useful for understanding human action and autonomy, which are crucial for an ethical act. In addition, the notion of AUB, as articulated by Newburg, is useful for understanding the ethical act as essentially unconscious. Finally, I have shown the importance of thinking about ethics in teaching, as our day-to-day realization of AUB is manifested in our contingent encounters with our students.

\section{Notes}

1. The reader might refer to Gregory Bateson's (1979) work on Russell's logical typing.

2. It is this bringing forth of a world of significance (that is missing [or not pre-existing]) that is the cognitive activity of the living system (Maturana \& Varela, 1992). 


\section{References}

Bateson, G. (1979). Mind and nature: A necessary unity. New York: Dutton

Boaler, J. (2003). Studying and capturing the complexity of practice-the case of 'Dance of Agency' In N.A. Pateman, B.J. Dougherty and J.T. Zillox (Eds.), Proceedings of the 2003 Joint Meeting of Psychology of Mathematics Education International and North American Chapter. CRDG, College of Education, University of Hawai i.

Boole, M. (1972). A Boolean anthology: Selected writings of Mary Boole-on mathematical education. Edited by D.G. Tahta. London: Association of Teachers of Mathematics.

Heidegger, M. (1977). Basic writings. New York: Harper and Row

Johnson, M. (1993). Moral imagination: Implication cognitive for ethics. Chicago: The University of Chicago Press.

Juarrero, A. (199). Dynamics in action: Intentional behaviour as a complex system. Cambridge, MA: The MIT Press.

Lacan. J. (1998). On feminine sexuality: The limits of knowledge, 1972-1973 (Encore: the seminar of Jacques Lacan-Book XX). New York: W.W. Norton.

Maturana, H.R. (1988). Ontology of observing: The biological foundations of self consciousness and the physical domain of existence. In Conference Workbook: Texts in Cybernetics, American Society for Cybernetics Conference. Felton, CA. 18-23 October.

Maturana, H.R., \& Varela, F. (1980). Autopoiesis and cognition: The realisation of the living. Boston: D. Reidel.

Mgombelo, J.R. (2002). Mathematics content-pedagogy knowledge: A psychoanalytic and enactivist approach. Unpublished doctoral dissertation, Edmonton, AB: University of Alberta.

Newberg, A., D'Aquili, E., \& Rause, V. (2001). Why God won't go away: Brain science and biology of belief. New York: Ballantine Books.

Varela, F., Thompson, E., \& Rosch, E. (1991). The embodied mind: Cognitive science and human experience. Cambridge: MIT Press.

Varela, F. (1992). Autopoiesis and a biology of intentionality. In Barry Mcmullin (Ed.), Proceedings of the Workshop on Autopoiesis and Perception, Dubbin: Dubbin City University.

Varela, Francisco J. (1999). Ethical know-how: Action, wisdom, and cognition. Stanford, CA: Stanford University Press.

von Foerster, H. (1992). Ethics and second order cybernetics. Cybernetics and Human Knowing, 1(1), 9-20.

Žižek, S. (1996). The invisible remainder: An Essay on Schelling and related matters. London: Verso.

Žižek, S. (1997). The plague of fantasies. London: Verso.

Žižek, S. (2000). The cartesian subject without the cartesian theatre. In K.R. Malone and S.R. Friedlander (Eds.), The subject of Lacan: A Lacanian reader for psychologists. New York: State University of New York Press.

Žižek, S. (2002). Cultural studies versus the “Third Culture." The South Atlantic Quarterly 101(1), 19-32.

Žižek, S. (2004). Organs without bodies: Deleuze and consequences. New York: Routledge. 


\begin{abstract}
About the Author
Joyce Mgombelo is an assistant Professor at Brock University where she teaches courses in mathematics education, teacher education and curriculum. Her research interests are in the areas of mathematics education, teacher education and curriculum studies. Dr. Mgombelo's ongoing research program includes studies of mathematics knowing and cognition, identity, teaching and ethics based on principles of human cognition, consciousness and subjectivity developed from complexity science (see the work of Varela, Thompson and Rosch, 1991; Varela, 1999; and Maturana, 1988) and psychoanalysis (see the work of Lacan, 1998 and Zizek, 1997, 2000).
\end{abstract}

(c) Copyright 2006. The author Joyce Mgombelo, assigns to the University of Alberta and other educational and non-profit institutions a non-exclusive license to use this document for personal use and in courses of instruction provided that the article is used in full and this copyright statement is reproduced. The authors also grant a non-exclusive license to the University of Alberta to publish this document in full on the World Wide Web, and for the document to be published on mirrors on the World Wide Web. Any other usage is prohibited without the express permission of the authors. 